\title{
REFORMA E NOVAS CONDIÇÕES DE CRENÇAS MODERNAS EM CHARLES TAYLOR
}

JOEL DECOTHÉ JUNIOR ${ }^{1}$

RESUMO: A pretensão deste artigo é a de expor o pensamento de Charles Taylor sobre a questão da Reforma ser um signo expandido que, de forma antecipada, contribuiu com o processo de secularização e o estabelecimento das novas condições de crença na era moderna. Para tanto, argumentamos que nesta configuração, o self, historicamente localizado na era antiga e medieval, vive numa tensão que o considera na condição de ser um ente poroso, o qual, em seus desdobramentos temporais para dentro da modernidade, ganha a condição de self protegido. Disto resulta que existe um significado que foi operado pelo processo histórico de desencanto e descrença, o qual, em meio à presença da divindade no mundo, passa por uma série de mutações. Tal configuração fomenta conflitos sociais que necessitam ser intermediados para gerar um equilíbrio complementar diante do desequilíbrio cívico estrutural numa sociedade que pretende se tornar linear. Outro aspecto importante nesta argumentação configurativa é o da função do tempo e o da desconstrução da ordem familiar anterior à modernidade em sua cosmovisão. Isto acontece desde os aspectos que se insurgem com o desdobramento do processo de secularização que avança as eras instaurando um mal-estar repleto de incognoscibilidades aporéticas. Por fim, aferimos que, para Taylor, a Reforma é fundamental no sentido de que, é com as pequenas reformas que se operam as mudanças significativas no cenário de vida pautado numa ética de afirmação da vida cotidiana propugnadas pelo significado das novas condições de crença que foram operadas por axiomas espirituais e culturais.

PALAVRAS-CHAVE: Reforma; Self; Modernidade; Secularização.

ABSTRACT: The intention of this article is to expose the thinking of Charles Taylor on the issue of the Reformation being an expanded sign which, in an anticipated way, contributed to the process of secularization and the establishment of the new belief in the modern era. For this we argue that in this configuration, the self, historically localized in the ancient and medieval era, lives a tension which considers it in the condition of being a porous being, which, in its temporal ramifications into modernity, acquires the condition of a protected self. From this results that there exists a meaning which was carried out by the historical process of disenchantment and disbelief, which, in the midst of the presence of the divinity in the world, passes through a series of mutations. Such a configuration foments social conflicts which need to be mediated to generate a complementary balance faced with the structural civic imbalance in a society which intends to become linear. Another important aspect in this

1 Doutorando em Filosofia pela Universidade do Vale do Rio dos Sinos (UNISINOS). E-mail: joeldecothe@yahoo.com.br. 
configurative argumentation is that of the role of time and of the deconstruction of the family order prior to modernity in its cosmovision. This happens beginning with the aspects which emerge with the unfolding of the process of secularization which advances the eras installing an ill feeling filled with aporetic unknowabilities. Finally, we verify that, for Taylor, the Reformation is fundamental in the sense that it is with the small reforms that the significant changes are carried out in the scenario of a life guided by an ethics of affirmation of daily life proposed by the meaning of the new conditions of belief which were carried out by spiritual and cultural axioms.

KEYWORDS: Reformation; Self; Modernity; Secularization

\section{Considerações iniciais}

A filosofia moral de Charles Taylor está eivada de elementos que necessitam de uma rigorosa atenção e aprofundamento teórico. Isto se justifica para que assim possamos ter uma melhor compreensão de suas proposições, devido à riqueza epistêmica que a sua ontologia moral nos oferece. Neste sentido, podemos denotar que as implicações éticas configuradas a partir da noção de afirmação da vida cotidiana seja algo que se erga desde o interior de seu pensamento como um hiperbem moderno. Esta noção de afirmação da vida cotidiana, que é entendida como uma espécie de hiperbem, significa para Taylor uma perspectiva densa de articulações que conferem sentidos éticos a sua ontologia moral. Tal concepção advém inicialmente da tradição teológica da Reforma Protestante, e desemboca no processo de secularização fomentado pelo Iluminismo racionalista. Taylor argumenta que a afirmação da vida cotidiana é um agir humano que está centrado na produção e reprodução da vida ligada aos elementos modernos do trabalho e da família. O cerne deste conceito de afirmação da vida cotidiana articulado no pensamento moral do filósofo canadense, versa sobre a construção da identidade do agente humano no curso dos desdobramentos culturais da modernidade ocidental. Assim, esta articulação de construção da identidade moral do agente humano, expressa a concepção de que a noção de vida boa para a espécie humana, não se encontra posta em alguma atividade de ordem superior que nos remeta para algo que esteja além da imanente vida hodierna, isto é, quer sejam tais considerações encaradas em termos de contemplação, ascetismo religioso ou até mesmo do governo estatal da vida dos cidadãos.

Quando pensamos na ideia de afirmação da vida cotidiana, isto significa, no pensamento tayloriano, que a própria existência no dia a dia entra em jogo, pois é aqui que temos a obtenção, pela via do trabalho, daqueles meios necessários para manutenção da vida e sua reprodução no seio da família, aquilo que Taylor tem em mente ao ponderar sobre a 
máxima do bem-estarismo, que pode ser utilizado pragmaticamente para a deliberação daquele bem que interessa à vida do agente humano. Para Taylor:

Talvez esta ideia tenha a sua gênese no cenário do puritanismo que coloca ênfase no imperativo do chamado divino, algo que com o processo de secularização se deslocou para o campo da concepção iluminista de que a felicidade humana estaria posta numa forma de vida que estivesse em plena consonância com a natureza. (TAYLOR, 2014, p. 160).

Desta forma, podemos coletar um dado importante a partir desta chave de leitura tayloriana, ou seja, o fato de que o aparecimento desta noção de afirmação da vida cotidiana tenha influenciado decisivamente os acontecimentos no decurso da história, com a força cabal da secularização no mundo latino cristianizado. Em seus últimos escritos, Taylor tem se ocupado cada vez mais com o problema da secularização e do papel ou poder da religião na esfera pública política, inerente às sociedades democráticas da contemporaneidade.

Fundamentalmente, em sua obra monumental Uma era secular (2010), o filósofo canadense busca escavar e articular os extensos movimentos ocorridos dentro da história da civilização ocidental que foi sendo erigida numa espécie de interação constitutiva, tanto cultural como espiritual, com a matriz religiosa cristã. Uma das aporias que podemos notar nesta escavação tayloriana é a de que o pensamento ou o imaginário moderno do ser humano ilustrado foi cada vez mais seguindo o curso de um tipo de forma de vida secularizada. Um dos baluartes desta progressão, em termos de secularidade, de uma maneira deveras curiosa acabou surgindo com o advento dos movimentos de reforma no interior da própria cristandade e, logo mais com o advento do deísmo iluminista. Ambas as configurações, de uma forma significativa, obnubilaram as respectivas cosmovisões antecessoras, isto é, cada vez mais a hegemonia da visão de mundo da idade antiga e do período do medievo foi sendo suplantada na ótica daquilo que Taylor propõe como fator problematizante que são as novas condições de crença introduzidas com o advento paulatino da modernidade.

Na perspectiva de Taylor, a fundamentação do passado se sedimenta no presente de modo que a ideia de onde o sujeito se encontra acaba se definindo pela historicidade de como se galgou tal estado de coisas no próprio tempo atual (TAYLOR, 2009). Em razão disto, quando nos detemos para analisar tanto os dilemas morais como os espirituais contemporâneos, o que se requer é uma extensa análise e avaliação filosófica de elementos que concernem respectivamente aos fatos históricos. Ademais, quando se avulta a necessidade de compreensão autointerpretativa do self, isto é algo que se determina em partes pela percepção de uma suprassunção da condição histórica e fenomenológica antecedente. Logo, o que se depreende disto é que, no esforço de autocompreensão da ideia substancial de onde nos 
encontramos no caudal da história e dos seus rumos teleológicos, levando em conta o objetivo que nós alcançamos, apoiamo-nos na reflexão de Taylor para compreendermos que "nesse sentido, há uma inescapável (embora geralmente negativa) referência a Deus na própria natureza da nossa Era Secular" (TAYLOR, 2010, p. 45).

Taylor tece uma análise fundamental em sua construção filosófica no que tange ao problema da secularização. Isto acaba sendo articulado no sentido de que se faz necessário destacar as implicações operadas pela obra da Reforma de uma forma extensiva. Aqui temos que levar certamente em consideração aqueles movimentos reformatórios que, desde o século XII, buscavam fomentar uma renovada prática de forma de vida e espiritualidade calcadas na imagem de personalidades carismáticas individuais, entre outros: Bento de Núrsia, Francisco de Assis, Martin Lutero etc. Em sua argumentação, Taylor denota que existe uma história subtracionista na qual se assevera que o surgimento de explicações científicas do universo geraram formas de vida em que as pessoas sofreram uma espécie de reorientação no que tange à hegemônica crença em Deus. Entretanto, Taylor pontua que esta visão da história deixa de lado o fato de que a ciência mecanicista levantou-se contra a consagrada crença num mundo encantado, e não necessariamente em oposição ao próprio Deus. Nesta direção, há que se levar em consideração que até mesmo as práticas seculares acabaram sendo postas sob uma base firme no que diz respeito à noção de providência conforme podemos ver no arcabouço conceitual do deísmo. Outro viés subtracionista residiria naquele esforço explicativo que indica que a modificação se deu por causa do desencantamento ou da necessária intenção de se buscar novas fontes morais referenciais que não sejam mais ligadas à noção de Deus. Isso desde o momento em que esta referência transcendente deixou de fazer parte da forma tradicional de se explicar o fundamento da realidade e, neste caso, como se outras bases já estivessem postas desde sempre e prontas para serem investigadas pela ciência e técnica moderna ascendente.

Esse tipo de argumento é rechaçado por Taylor, pois as possíveis interpretações variantes existentes no que concerne à noção de plenitude não se encontravam imediatamente acessíveis a todas as pessoas. Se a ciência cumpriu o papel de contribuir para o processo de desencantamento do mundo e a abertura de uma senda promissora que resultou no humanismo exclusivo, algo ainda recai sobre esta ponderação num outro fator importante que é o da necessária sobreposição de confiabilidade nos poderes inerentes ao ordenamento moral social. E isto foi algo que certamente recebeu uma extensa influência participativa da forma de vida religiosa. Para Taylor, somente na corrente filosófica epicurista é que residiu efetivamente no 
mundo antigo, a possibilidade de um "real humanismo exclusivista" (TAYLOR, 2010, p. 40). Entretanto, a aceitabilidade deste humanismo exclusivista não se deu de uma forma pacífica e imediata. O que aconteceu foi que este humanismo foi erguido por meio de uma série de etapas estribadas na existente via de formas prolépticas de vida cristã. Dessarte, Taylor explica que analiticamente os pontos fundantes destas modificações dos contextos de crenças se dão por meio de três vieses fundamentais que fizeram um contraponto para que se estabelecessem as nuances das novas condições de crença.

Desta forma, vejamos rapidamente as devidas distinções propositivas que balizam as bem elaboradas reflexões de Taylor no que concerne ao problema da redefinição do significado da secularização: (i) O mundo natural onde as pessoas viviam, no qual elas possuíam o seu lugar naturalmente no cosmos que imaginavam, dava testemunho do propósito e da ação divina; (ii) Deus estava também implicado na própria existência e funcionamento da sociedade (não descrito como tal - esse é um termo moderno -, mas como cidade ( $\pi$ ó $\left.\lambda \iota_{\varsigma}\right)$, reino, igreja ou o que for). Um reino poderia ser concebido apenas como fundado em algo mais elevado, ou seja, naquilo que transcenda a mera existência e ação humana no tempo secular; (iii) "As pessoas viviam em um mundo encantado" (TAYLOR, 2010, p. 42). Então, logo percebemos que na construção tayloriana o que se visa analisar desde um ponto de vista filosófico e histórico são aquelas mutações surgidas com as novas condições de crença em curso, aproximadamente de 1500 d.C. em diante, promovidas pelo processo de secularização. Por esta razão, num primeiro momento vamos nos deter aqui nos pontos que desenvolveremos abaixo, de uma forma aproximativa na questão da obra expansiva da Reforma em sua variabilidade de significações.

\section{O self entre a porosidade e a proteção: o significado da fratura operada pelo processo de desencanto e descrença em meio à presença divina no mundo}

O self, num primeiro momento, na visão de Taylor, viveu o processo de secularização em uma espécie de tensão progressiva que dialeticamente, em termos de desconstrução, imprimiu um processo de desencantamento e descrença no mundo latino cristianizado. Logo, Taylor argumenta que ao que tange a vida do self existe, respectivamente, aquela tensão entre a porosidade do self e a sua condição de ser protegido. No pensamento de Taylor, o self pode ser interpretado em muitos sentidos, pois este não se encerra nas estruturas da vontade, da racionalidade ou mesmo no campo da ação. Desta maneira, o pensamento ontológico moral 
tayloriano, nutre aspectos que são importantes em termos hermenêuticos, quando se trata de definir o sentido daquilo que constitui o que seja o self em se agir moral. Porém estes somente existem e fazem sentido no pano de fundo das indagações morais, que compõem as partes de uma gama de articulações ligadas aos bens constitutivos que abarcam a vida e a construção da identidade do agente humano. Logo, para Taylor existem modos de racionalidade, vontade e ação, pois tais dinâmicas envolvem a vida do self em sua relação com o bem. Assim, a ontologia moral tayloriana entende o sentido da vida do self como autointerpretativa. Contudo, temos uma abertura que nos indica que Taylor provavelmente extrai esta noção da filosofia heideggeriana, encontrada no quinto capítulo ("O ser-em como tal”) de Ser e Tempo (2008), em que o filósofo alemão cunha a noção ontológica de que o ser aí é disposto compreensivamente junto-a-mundo. Isto significa que o ser já sempre se move e se apoia em uma determinada disposição das práticas e dos discursos, que são inevitavelmente afetadas em vistas de uma nova vida relacional com o mundo. Desta forma, o self em Taylor tem várias possibilidades de compreensões possíveis em sua imanência nas configurações articuladas a partir do horizonte de nossas fontes morais. Em síntese, podemos inferir que Taylor forja quatro momentos de sua análise ontológica mora do self: “(1) A relação entre o self e o bem por meio de nossas avaliações fortes; (2) O self e suas configurações; (3) O self enquanto auto-interpretação e (4) O modo dialógico do self' (PEREIRA, 2008, p. 91). Aqui temos basicamente as definições que Taylor utiliza para a sua investigação em torno do agir moral da vida do self.

$\mathrm{Na}$ argumentação tayloriana surge a proposição de que o desencantamento do mundo foi tomando paulatinamente o seu espaço, algo que imprimiu na ordem moral o processo de desconstrução daquela mentalidade fantástica que imperava na sociedade da época. Sendo assim, o que aconteceu foi a abolição da crença na presença e ação de espíritos e potências que garantiam a vigência das fontes morais hegemônicas no mundo da época. Em lugar desta forma de vida encantada, o que entrou em voga foi uma forma de pensar, sentir e cultivar os axiomas da espiritualidade que se encerraram na mente racionalista moderna. A mente racionalista tornou-se o campo privilegiado em que a autoconsciência interior, além de ganhar valor, deveria ser cultivada em termos de uma sã vivência social. Na dinâmica que surge a partir desta constatação, temos a instauração da noção de formas de autocontrole e de autodescoberta, que foram sendo erigidas durante o longo processo de internalização das fontes morais que daí surgiram. O que Taylor articula em sua argumentação é que houve uma espécie de deslocamento do estado de coisas encantadas para outro estado de coisas que leva 
em conta a condição de desencanto racionalista, pois antes disso existia somente um modo ingênuo de viver. Esta forma de abordar o problema da secularização e as novas condições de crença marcou a constituição da identidade do self moderno. Taylor expressa que o seu interesse nuclear está posto no deslocamento que ocorreu da condição de encantamento para a de desencantamento:

\begin{abstract}
Estou interessado na compressão ingênua, pois minha alegação será a de que uma mudança fundamental ocorreu nessa compreensão na passagem para o desencantamento. Isto não é o mesmo que sugeri acima sobre a questão da existência de Deus e outras criaturas espirituais. Ali, passamos de uma aceitação ingênua da sua realidade para uma percepção de que afirma-los ou negá-los é entrar em um terreno controverso; não existem mais teístas ingênuos, exatamente como não há mais ateístas ingênuos. Porém, subjacente a essa mudança está aquela sobre a qual estou falando agora na nossa percepção do nosso mundo, de um mundo no qual esses espíritos simplesmente estavam ali sem problemas, exercendo sua influência sobre nós, para outro no qual eles não estão mais e, na verdade, no qual muitos dos modos como estavam ali tornaram-se inconcebíveis. A sua não influência é o que experienciamos ingenuamente (TAYLOR, 2010, p. 47).
\end{abstract}

No universo marcado pelo encantamento, os limites entre o agir moral individual e o poder impessoal não estavam demarcados com a devida clareza. De modo que as forças mágico-transcendentes, que se acreditava circular entre os humanos, e isto de um modo indutivo em termos de significados que atingiam o modo de vida das pessoas no âmbito daquilo que é fantástico. Tal operação foi se tornando uma amálgama de forças morais externalizadas que, de uma forma personificada ou não, acabou não fazendo parte da visão de mundo das bases substantivas de vida dos modernos. Na perspectiva da modernidade, as coisas se deram de modo anverso, pois o significado advém em boa medida de uma forma endógena de viver, pois só ganha sentido quando atinge em termos naturais a mente e o corpo orgânico. Esta questão da individualidade seria uma das fontes morais mais importantes do pano de fundo moral da vida dos modernos. Algo que se ergueu como "a maior conquista da civilização moderna. Em princípio, as pessoas não são mais sacrificadas às demandas de ordens supostamente sagradas que as transcendem”. (TAYLOR, 2011, p. 12).

Antes do processo de secularização se intensificar, os objetos fantásticos ainda carregavam consigo poderes mágicos, pois estes detinham uma força causal que operava como que num lugar de onde emanavam poderes que recebiam o crédito de serem modificadores de resultados no mundo natural em termos de ordem moral, quer seja para o bem ou para o mal. Porém, com o advento do desencantamento, o que vem a tona é a realidade de que os objetos perdem o sentido de serem portadores e canais de forças miraculosas. Para Taylor (2004), o mundo físico toma a dianteira das explicações naturais em 
termos de oferecer as leis causais dos fenômenos, algo que se instala de uma forma que não mais delega à moralidade humana todas às razões das ocorrências dos fatos vividos. Seguindo este caminho, Taylor expõe que a fascinação presente nas condições de crença antiga e medieval recebe forte influência de espíritos e seres extraterrenos, e ainda de algo que era mais grave para estas mentalidades, isto é, o fenômeno das possessões demoníacas. Logo, a questão dos significados de crença não está encerrada apenas na interioridade do sujeito, mas existem também as crenças exógenas e o limite de onde se inicia e se finda o significado destas em que não se pode demarcar com precisão a sua topografia limítrofe, pois o que temos é certa condição de porosidade presente na vida do self que ademais deixará de existir oficialmente.

Neste contexto, Taylor indica que, além das possibilidades teoréticas, a vida do self é jogada na realidade concreta do mundo e, ademais, esta seria a "forma como percebemos as coisas e, portanto parecemos experienciá-las" (TAYLOR, 2010, p. 54). Essa situação se configura a partir de uma circunstância em que o fator nevrálgico se manifestava por meio de uma condição vulnerável e inerente ao contexto de significados referentes ao mundo antigo e medieval. Esse contexto de significados levava adiante ideias, crenças e práticas ligadas à obrigação, à dívida, à culpa e ao castigo que, com o andamento do processo de desencantamento, foram caindo em desuso. Desta maneira, Taylor realiza uma distinção precisa a respeito da condição do self, ou seja, o que temos é o self protegido dos modernos, que estabelece limites bem delineados entre aquilo que seja interior e exterior na vida moral.

De outro ângulo, temos o self poroso que perpassa o mundo antigo e medieval. Este self é vulnerável a influências exógenas, algo que faz um contraponto em relação à condição do self protegido. No caso do self protegido, existe a possibilidade de distanciamento de tudo aquilo que está fora da mente, de modo que o limite se torna uma espécie de proteção, pois sendo assim, as coisas necessitam atingir de fora o sujeito pensante. $\mathrm{O}$ self dos modernos tem as condições de se constituir como uma mentalidade de invulnerabilidade, pois a partir deste momento este se torna o conferidor de significados para aquilo que está a sua volta. Um bom exemplo disto é aquele que Taylor nos oferece sobre o self pontual que "chega a seu pleno desenvolvimento com Locke e com os pensadores do Iluminismo que ele influenciou" (TAYLOR, 2013a, p. 210). Quando falamos do self vulnerabilizado, salta aos olhos a condição de crença na ação exógena de entidades espirituais: tais como anjos e demônios ou forças cósmicas, que refletem a noção de que os seus sentimentos fortes não se encontram sob um autocontrole cerebral e tecnicamente preciso. 
Os reflexos desta tensão demonstram que o self protegido vai ganhando certa autonomia de modo que este continuamente vai se desengajando de toda e qualquer coisa que ultrapasse os limites de sua própria condição fronteiriça, a qual este mesmo de uma forma autônoma estabelece para si mesmo na perspectiva de constituição do axioma do autocontrole como uma fonte moral inovadora. O self protegido define cada vez mais com precisão e evidência a sua condição individual, pois com isto este vai se tornando continuamente mais livre das influências das coisas que parecem ser incontroláveis. Sendo assim, temos uma visão de mundo que vai se configurando em termos de modificações que chegam ao ponto de tratar a própria lei natural como algo passível de se tornar um fenômeno domesticável a despeito de sua rigidez. Este seria um dos frutos do mundo desencantado. O que se depreende disto é que no mundo encantado existia uma tensão ambiguamente fomentada por potências contrárias entre si, por esta razão Deus surgia sempre como o assegurador da ordem moral atômica e holista. Mesmo que no fundo da questão a ideia de Deus não era uma variante, mas expressava a sua superioridade hierárquica normativa em termos de crença geral no mundo encantando. A mutação acontece quando "o self protegido desbancou tal normatividade hierárquica" (TAYLOR, 2010, p. 59). Um dos fatores que se tornou preponderante nessa mutação do pano de fundo social moderno foi a ação positiva direcionada ao humanismo exclusivo. Essa modificação no pano de fundo operada por este humanismo criou as condições necessárias para o desprendimento do self em relação a Deus e, o fomento da superação da visão cosmológica pré-moderna. Desta forma, o humanismo exclusivo se avultou como uma mera possibilidade não concretizada, porém viável por ser pautada pelo imperativo da razão crítica.

No mundo que antecedeu a modernidade, a noção da existência de seres sagrados era uma realidade irrenunciável. Por esta razão, o self em sua condição protegida vai tomando ciência a respeito da possibilidade de determinado desprendimento daquilo que o circunda em termos naturais e da até então ordenação moral que vinha imperando de uma forma completamente factível. Isso ocorre para o self em seu estado poroso de sua vivência dentro de um mundo encantado que significava ser uma espécie de agente que compunha uma sociedade que lhe oferecia ameaças exógenas que poderiam lhe afetar por meio de forças malignas que rondavam todo um conjunto de ações sociais que comportavam a vida do agente humano em seu contexto de significados místicos. Isto certamente gerou algumas consequências sociais em termos de desprendimentos e mutações na vida cotidiana do self protegido em relação ao pano de fundo da forma de vida anterior. Neste aspecto, o que se leva 
em conta, nesta ordem moral, é uma questão muito importante no sentido de que havia naquela sociedade encantada a necessidade da existência de um consenso de sustentação e manutenção de uma ortodoxia teológica que fosse determinante para que se evitassem as consequências das possíveis fraturas sociais que poderiam surgir com a queda do antigo regime fundado em crenças transcendentes. Outro aspecto que precisa ser ressaltado é o da forma de vida religiosa com que as pessoas experimentavam aquela sociedade em seu funcionamento encantado. Pois a condição de crença era monolítica, porque Deus e as forças encantadas detinham o centro das atenções em termos de causalidade dos fatos da vida diária.

A ordem moral encantada era pautada significativamente nesta esfera social que privilegiava o sagrado e, de certa maneira se tornava inconcebível que as coisas ocorressem de um modo diferente. Isto era inimaginável pelo fato de este ser o modo de vida da sociedade como comunidade, sendo este um contraponto com a noção de self protegido como bem assinala Taylor:

\footnotetext{
O self protegido é, essencialmente, o self que está ciente da possibilidade de desengajamento. E o desengajamento é frequentemente realizado em relação ao entorno total de uma pessoa, natural e social. Mas viver no mundo encantado e poroso de nossos ancestrais era inerentemente viver em sociedade. Não era apenas uma questão de que as forças espirituais que me afetavam geralmente emanavam das pessoas à minha volta, como, por exemplo, o feitiço lançado por meu inimigo, ou a proteção assegurada por uma vela que fora abençoada na igreja da paróquia. Muito mais fundamental é que essas forças geralmente nos afetavam como uma sociedade e nos defendíamos delas como uma sociedade (TAYLOR, 2010, p. 60).
}

Conforme podemos notar, a realidade divina era uma força que sustentava a coesão social, isto tornava a possibilidade de se ter um imaginário social diferente do hegemônico quase que impossível. Porque o elemento central desta ordem moral porosa e encantada, para garantir o seu funcionamento, era fundamentado nas condições de crença religiosa comunitária. Neste universo, o imaginário social mágico era representado por objetos, tais como relíquias, narrativas de supostos fatos miraculosos etc. Logo, "num universo assim imaginado, era praticamente inevitável acreditar em Deus” (RODRIGUES, 2015, p. 182). Aqui temos a igreja como instituição que chancela estas práticas de crença. Ainda hoje, com o decurso do processo de secularização, nós temos situações onde as crenças são institucionalizadas. O que marca a distinção deste contexto de significados anterior em relação ao posterior é algo que indica o fato de atualmente as crenças serem de ordem imanente e as suas referências estarem atrelas aquilo que é do campo antropológico. Pois, quando pensamos nos fundamentos das sociedades democráticas liberais e num de seus órgãos mais importantes, que é o caso do Estado de direito, que podemos imediatamente 
identificar isto. Nesta configuração social, os pressupostos desta instituição são acolhidos pelos cidadãos como que absolutamente verdadeiros e infalíveis de modo que paira a quimérica ilusão de que sem estes pressupostos legais seria impossível viver. Porém, nós hoje vemos e podemos encontrar um contraponto "nas transformações que o pano de fundo político tem demonstrado com a desconstrução e falencismo do modelo de Estado moderno" (BITTAR, 2011, p. 31).

Assim, mesmo em meio às crises inevitáveis, para Taylor são os valores democráticos que importam na perspectiva do espírito político liberal cooperativista e holista que não pode ser extinto. O filósofo canadense indica que a "ameaça ao espírito democrático pode estar presente em alguns interesses de poder, que tem como base o princípio da razão instrumental e o próprio interesse das pessoas" (TAYLOR, 2013b, p. 42). Este tipo de operação enfraquece cada vez mais o próprio Estado de direito democrático e gera uma fileira de pessoas que não trabalha mais em prol dos valores democráticos. Quando pensamos em termos de processo de secularização a partir das intuições taylorianas, podemos encontrar a noção de que uma sociedade secularizada imanente ao universo democrático não é uma sociedade que abole as crenças religiosas em algo transcendente em nome de um suposto laicismo. Mas, se pensarmos nos significados das avaliações fortes realizadas pelo self moderno e que são pautadas numa configuração vinculativa entre identidade e moralidade, o que se tem são espaços onde as crenças espirituais e morais não são determinantemente dirigidas a uma divindade ou qualquer outra espécie de transcendência. Contudo, existem outros espaços morais que se instituem como algo totalmente antropologizado e imanente ao campo da esfera pública política onde a religião tem o seu espaço de manifestação garantida na cooperação que pode delegar as gerações com os seus valores comprometidos com o bem e ajustiça.

\section{Os conflitos sociais e a intermediação executada entre o equilíbrio complementar e o desequilíbrio cívico estrutural}

Em sua investigação sobre o processo de secularização, Taylor pontua que inerente a este existiu uma gama significativa de conflitos sociais que marcaram tanto o mundo antigo como o medieval. Desde este ponto de vista temos as demandas que o cristianismo como religião preponderante foi impondo como é o caso da noção de autotranscedência. De outro ângulo, temos as instituições e as práticas sociais que objetificam a fomentação do florescimento humano. Em síntese, o que se depreende é que os conflitos instaurados entre as 
práticas imperativas advindas da fé cristã e das necessidades da vida hodierna se avultavam estrutural e continuamente. Tanto nas altercações entre as vocações de renúncia como eram as celibatárias e, retrocedendo, a noção de éticas guerreiras, seja nas festas de carnaval ou nos ritos que invertiam a ordem moral, o axioma da complementariedade de funções gerava determinado equilíbrio entre as condições de conflito social que continuamente ocorriam em suas diversas formas e variáveis, e aquilo que Taylor chama atenção ao argumentar dizendo que "a tensão emerge de várias formas" (TAYLOR, 2010, p. 62).

Um dos problemas que Taylor põe em questão num diálogo com Turner no que se refere à antiestrutura que representava o carnaval, seria a ideia de que na ordem moral que este fenômeno se localizava não se constitui como a mais relevante do arranjo social de então. Porém, o fato é que esta não se mostra como a última ordem existente, mas o que vem a termo é a comunidade a qual esta serve, pois tal comunidade sustenta valores de cunho igualitário. Logo, esta sociedade é o produto de configurações que comportam fenômenos festivos que assumiam um tom de complementariedade, pois certamente existia a necessidade dialética de oposicionalidades, contudo estas não podiam ser vivenciadas de uma forma simultânea. Este universo necessita de um tipo de ordenamento moral que comporte a possibilidade da desordem, pois é assim que se enovelam tanto a estrutura com seus códigos morais como a antiestrutura com o seu impulso de rechaço de todo e qualquer tipo de código rígido.

Para Taylor, no mundo antigo a vida tinha os seus momentos de subversão em que a configuração de uma antiestrutura ativa num determinado contexto social e espiritual era certamente vasta. De modo que, mesmo diante das estruturas legítimas, o processo de secularização foi ganhando força na esfera pública política. E neste aspecto tem de ser levado em conta que na modernidade a entificação dos códigos demonstrou certa intolerância em relação às antiestruturas, isto foi algo que contribuiu para superação dos limites que complementavam as visões de mundo antiga e medieval. No mundo dos modernos, o carnaval e a empresa revolucionária não tinham qualquer tipo de consonância. A razão forte para que isso acontecesse é a de que, se esta configuração carnavalesca se erguesse como antiestrutura que ganha força na intenção de legitimar a própria estrutura e assim equilibrar os conflitos sociais, teríamos uma assimetria sistêmica. Já com a questão da revolução social o que se busca como algo possível é o ato de se pensar que também possa existir uma antiestrutura que se erga para exterminar toda ordem moral vigente e assim substituir o arranjo social imperante, no sentido de resolucionar desequilíbrios dentro da nova ordem moral implantada, que tem a pretensão de ser sequencialmente estabelecida em termos de uma nova estrutura. 
Esta sequencialidade estrutural acaba se tornando uma marca do liberalismo na modernidade. Entretanto, tal ordenamento se mostrará limitado e insuficiente em resolucionar os problemas sociais em sua totalidade. Assim, segundo Bobbio (2004), a moderação e o enfraquecimento do ideal das luzes de uma forma positivista, objetivava no que tange ao campo do jurídico, regular desde o ponto de vista do direito excessivo as ações humanas em sua totalidade para implantar a noção de direitos humanos. Esta intencionalidade jurídica acaba demonstrando que o afã de se ter o controle da vida do self por meio de um único código se revela como uma espécie de quimera, no sentido em que a própria noção de vida, na esfera privada em que a força da antiestrutura, pode vir desabrochar com vigor, dando assim ao sujeito um lugar onde o mesmo possa vivenciar as suas potencialidades criativas em comunidade onde o self experimenta as amplas tensões sociais entre o atomismo e holismo moral. Neste sentido argumenta Taylor:

\footnotetext{
Embora na teoria e na prática regimes liberais desse tipo pluralista tivessem sido desenvolvidos, as consequências do eclipse da antiestrutura foram muito mitigadas. Poderíamos até mesmo dizer que a antiestrutura recebeu um novo tipo de lugar nessas sociedades, no domínio privado. A distinção público/privado e a ampla área de liberdade negativa representam a zona equivalente nessas sociedades aos festivais de inversão em suas predecessoras. É aqui, na nossa própria, entre amigos e família, ou em associações voluntárias, que podemos "cair fora", jogar para o alto nossos papéis codificados, pensar e sentir com nosso ser por inteiro, e descobrir várias formas intensas de comunidade. Sem essa zona, a vida na sociedade moderna seria invivível (TAYLOR, 2010, p. 72).
}

Sendo assim, o que fica claro para Taylor é que o regime liberal desde o seu nascedouro em plena modernidade carrega consigo uma série de tensões e problemas. As suas promessas de harmonizar e estabelecer um igualitarismo contratual a todo custo não deixam de se constituir como mera promessa. Os conflitos precisam ser reconhecidos e desta feita o equilíbrio é um problema, isto instaura uma necessidade de debater profundamente os próprios fundamentos do liberalismo e suas deficiências. De modo que apenas o reconhecimento desta debilidade é que pode indicar um caminho reformista mais concreto e lúcido no seio liberal. Então, passemos ao próximo tópico onde o tempo e a erosão da ordem moral antiga se insurge como um mal estar evidentemente peculiar na vida do self em sua transição da condição de porosidade para a de proteção no processo expansivo da obra da reforma que a secularização tem posto em curso, e que traz à baila as novas condições de crença da modernidade. Neste sentido é que Taylor pretende nos mostrar a crença e a descrença como "modos alternativos de vida moral/espiritual, notadamente na dimensão da 'plenitude' cuja realização se dá no quadro imanente da uma modernidade ocidental 
condicionada pela erosão da certeza imediata e pelo fim da fé religiosa ingênua onde a crença em Deus deixou de ser axiomática" (ARAUJO, 2012, p. 19-20).

\section{A função do tempo e a desconstrução da ordem familiar: aspectos insurgentes de uma aporética era secular}

A função do tempo nesta dinâmica problematizada por Taylor dentro daquilo que seja a redefinição do significado da secularização é de tamanha importância. Como podemos resumir, são três as perspectivas arroladas pelo filósofo canadense: (i) a função dos eclipses do mundo marcada pelo encantamento; (ii) a do sagrado ôntico delineado pela institucionalização estatal; (iii) o papel do tempo da complementaridade. Em Taylor estes operadores do tempo são encarados como peças fundamentais no processo de secularização. Porém, cabe frisar que o filósofo canadense reconhece que estas categorias não dão conta de explicar em sua totalidade este fenômeno. Logo, faz-se necessária a realização do empreendimento de uma distinção no que tange a própria concepção de tempo. Segundo Taylor (2010), a forma de ver o tempo antes do advento da modernidade era arquitetada pelo tempo comum ou secular em razão dos tempos superiores. Esta gama matizada de tempo tinha a função de reordenar o tempo comum secularizado por meio de distorções e inconsistências da vida hodierna.

Os tempos superiores se matizam em três formas: (i) o tempo da eternidade que era um legado vindo de Platão, em que o ser em sua plenitude está localizado desde um ângulo exógeno ao tempo do cotidiano e por isso não pode ser atingindo ou mudado em seu substrato. Isto é algo que se opõe a noção de tempo secularizado que seria um tempo inferior, sendo por isso não tão relevante; (ii) o tempo marcado pela visão propriamente cristianizada, que tem a sua base na compreensão de Santo Agostinho sobre o fenômeno, ao entendê-lo a partir daquilo que se vive na união entre o passado e o presente que serve como projeção para o futuro. A repercussão desta compreensão do tempo irá atingir a noção de "três ekstaseis de Heidegger" (TAYLOR, 2010, p. 77). A implicação aqui é a de que ao se elevar até a perenidade se participa por um instante da divindade; (iii) a noção de um tempo fundacional ou primordial que denota uma ordenação das coisas em que teria acontecido o estabelecimento das condicionantes da realidade do tempo presente.

A partir desta argumentação, Taylor nos mostra que o tempo secularizado em tensão com os tempos superiores acabou sendo suprimido entre os modernos, de modo que para estes 
a percepção de tempo está atrelada a uma ideia de que a vida está inserida em um fluxo permanente e jogada numa condição puramente imanente e horizontalizada. Tal imbricação presente entre o tempo secularizado e os tempos superiores não faz mais tanto sentido para mentalidades desencantadas. Isto se tornou um dos pressupostos que fundamentou o que tem se tornado a estrutura da vida em uma sociedade secular. Desta maneira, os imaginários sociais modernos e a própria ordenação moral foram sendo configurados por esta compreensão de tempo. O problema se espraia para a suposta contribuição que a ciência tenha oferecido para estas mutações. Taylor admite que a ciência tenha contribuído no século XII com a sua proposta mecanicista, mas não cabe dar a ciência o posto de ter sido a única causadora de tais fenômenos.

Entrementes, outro fator ganha destaque, ou seja, é aquele que nos remete a noção de como se conduz a forma de vida e o seu ordenamento. Pois, na modernidade o que vale é o modo como as disciplinas de uma ordenação civilizada podem organizar o tempo como "jamais havia sido feito ao longo da vida moral e histórica humana" (TAYLOR, 2010, p. 81). Um dos desvios desta situação foi a intenção da construir uma formação social que fosse pautada na linearidade com valores regulatório, rigorosos em termos de controle e que Weber definirá como uma espécie de gaiola de ferro. Fazendo um contraponto com esta ideia, Taylor problematiza com a posição de Walter Benjamin que propõe uma noção de "tempo homogêneo e vazio" para afirmar a existência de variados espaços de tempo, mesmo que isto seja vedado a comparações no que diz respeito ao estágio de tempo dos antigos e medievais e ainda que seja insuficiente para dar conta do problema moderno. Veja como Taylor argumenta a respeito:

É evidente que o tempo neste mundo de inversão e antiestrutura não pode ser $o$ "tempo homogêneo, vazio" que Benjamin torna central para a modernidade. O tempo do carnaval, por exemplo, é cairótico; isto é, a linha de tempo encontra nós cairóticos, momentos cuja natureza e lugar exigem inversão, acompanhados por outros que demandam rededicação, e outros ainda que se aproximam do Advento: Terça-Feira de Carnaval, Quaresma, Páscoa. Agora, existem nós cairóticos nas histórias que contamos sobre nós mesmos no nosso tempo. As próprias revoluções são compreendidas por seus herdeiros e defensores como tais momentos cairóticos. E a historiografia nacionalista está repleta de tais momentos. Mas o que mudou é aquilo em torno do qual esses momentos se reúnem. Na era pré-moderna, o campo organizador para o tempo comum deriva daquilo que quero chamar de tempos superiores (TAYLOR, 2010, p. 74-75).

Esta questão do tempo nos leva para uma posição onde o esvaecimento da antiga visão de mundo familiar e a erupção de um mundo incognoscível começa a despontar. Uma das movimentações reformatórias foi a da nova compressão do lugar onde se vivencia o tempo, no 
deslocamento de uma visão cosmológica cerrada para um olhar moderno calcado na neutralidade. No mundo antigo, o olhar cosmológico se encerra numa finitude e limitação bem demarcada, pois o senso de ordem e hierarquia perpassava toda vida individual ou social. No caso da religiosidade judaico-cristã pautada na Bíblia, a visão de mundo cosmológica é uma ideia forte. Sendo esta a herança cultural do Ocidente fica muito difícil dizer que esta influência não atingiu as eras que se desdobraram deste lado do mundo, e que a própria constituição desta sociedade certamente pode ter sido definida durante muitos séculos em termos de teleologia por esta metanarrativa. Conforme Ribeiro (2010), quando pensamos em uma narrativa da secularização, a noção de cosmos foi se diluindo na modernidade, pois o ser humano acessou um universo onde a ordem lhe apresentava leis naturais rígidas que precisam ser manipulas. Esta era a consequência epistemológica central que a ciência tinha formulado. O deslocamento também teve um aspecto ligado à espiritualidade num sentido de que se passou de uma crença teísta ingênua para uma configuração deísta mais perspicaz e consequentemente para uma ordem desengaja e impessoal posteriormente. O grande resultado disto tudo é que se obteve uma visão do mundo como algo incomensurável e incognoscível, de modo que agora serão fomentadas aquelas novas condições de crença e também descrença em razão do desancamento reformista.

A importância desta remodelação encontra-se nos meandros da alteração do debate, que acabou sendo revisado e que afetou as condições de crença e descrença da época. Isto certamente imprimiu um renovado senso de abertura epistêmica e forjou uma série inédita de possiblidades de se rechaçar a autoridade da fé cristã com as suas exigências de autotranscedência e forma da vida baseada na ortodoxia. $\mathrm{O}$ que entra em vigência é uma compreensão de mundo que é regida em sua funcionalidade que privilegiou a formulação de uma série de doutrinas de cunho providencial. Assim, temos algo que foi fundamental para a construção do self dos agentes que assumiram uma identidade impessoal e desengajada em uma realidade moderna neutra. Para Taylor, a progressiva situação de desencanto fortaleceu a autoconfiança nas potencialidades do self em suas manifestações autoexpressivas e de avaliação forte diante do novo pano de fundo espiritual e cultural. O self moderno começa a definir cada vez mais a sua identidade fundamentada numa ordem moral que pode ser construída na imanência horizontal. Uma das razões que Taylor considera ser pontuais para o modo de vida levado neste contexto é a Reforma que faz acontecer modificações ímpares na sociedade. Porém, para Taylor a Reforma é algo bem amplo, de modo que existem pequenas reformas dentro da cristandade e fora dela. Aqui o individualismo será a marca que ajudará a 
suplantar a "mentalidade mágica que tinha como intenção controlar a ação de Deus" (RIBEIRO, 2010, p. 150).

A luta destas pequenas reformas foi vencer um poder pastoral que utilizava o expediente do medo e que gerava uma condição agnóstica de ansiedade e que não promovia a busca de uma nova vida em direção à plenitude do bem. Enfim, assim temos as condições necessárias para compreendermos em parte a razão porque Lutero e seus companheiros obtiveram sucesso com a proposição de uma teologia da salvação atomizada somente pela fé. Dentro deste escopo teológico a soberania de Deus é reconhecida e ocorre um nivelamento das personalidades. A razão desprendida tem a sua gênese ao notarmos que Deus não pode ser controlado e subjugado por lugares, objetos ou ritos. Aqui temos a afirmação da ética da vida cotidiana, pois a máxima é a de se viver a vida cristã no campo do ordinário, do hodierno que é algo acessível a todas as pessoas e não apenas a uma hierarquia separada por Deus. Então, podemos inferir que para Taylor a Reforma de uma forma expandida descontrói o cosmos encantando, gerando assim a possibilidade da construção de um humanismo exclusivista que promova uma espécie de sociedade moderna que propugna o objetivo da autorrealização humana com a pretensão de plenitude. Tudo isto atrelado ao contexto das novas condições de crença embasas numa ética da autenticidade em que o self deve construir e forjar a sua identidade num fundacionalismo baseado na razão crítica, procedimental e formalista no decurso de sua vida moral.

\section{Considerações finais}

Neste artigo buscamos apresentar um pouco daquilo que Taylor desenvolve no primeiro capítulo de sua obra monumental Uma era secular (2010). Taylor é um dos filósofos contemporâneos que se ocupa em escavar novos significados para o fenômeno da secularização. O processo de secularização não resulta na postura de menos religião na esfera pública e ainda na noção de um Estado neutro. Para Taylor, a secularização não significa ausência ou privatização do sagrado. Porém, a partir da Reforma isto significa que as condições de crença foram modificadas e o seu sentido foi remodelado e pluralizado. Pois se, antes do advento da modernidade era inimaginável pensar na possibilidade de existir alguém que não acreditava em Deus publicamente, a partir do momento em que o desencantamento racionalista moderno entrou em vigor, crer em Deus passou a ser apenas uma possibilidade entre tantas outras na ascendente modernidade. 
Contemporaneamente, este processo de secularização atinge as questões referentes aos Estados liberais democráticos que se dizem laicos, mas para Taylor isto não deveria ser sinônimo de uma prática institucional antirreligiosa. Isto da mesma maneira pode ser encarado, no sentido de que quando alguém busca o sagrado não se deve querer indicar que este esteja exclusivamente vinculado às instituições religiosas. Até porque com o advento da Reforma de uma forma ampla, o que nós podemos perceber é que o processo de desprendimento da razão resultará no fomento de um humanismo exclusivista e no próprio Iluminismo mecanicista e racionalista, que com o seu recorte crasso numa razão puramente instrumentalizada acaba ganhando o seu maior representante na própria ciência. Taylor apresenta-nos, desde um ponto de vista analítico-historicista, aspectos de desenvolvimento do cristianismo em seus elementos seculares no mundo latino de modo que os fatos apresentados são aqueles do desaparecimento e supressão de uma antiga forma de vida de um self poroso para uma nova forma de vida de um self protegido. É com o significado da mutação destas novas condições de crença que Taylor se ocupa, sendo a obra da Reforma um baluarte paradigmático da fé nos impulsos remodeladores do contexto de vida moderno.

Nesta investigação sobre os renovados significados da secularização, Taylor nos apresenta uma série de experiências por meio de extraordinárias ações espirituais e culturais que a civilização latina foi articulando com o deslocamento da ordem moral antiga para as novas configurações de construção da identidade do self, em termos de condições de crenças na então nascente ordem moral moderna. Em suma, como indica Costa (2015), a construção realizada por Taylor nos mostra a transição que inclui muitos personagens e momentos históricos significativos. A mentalidade moderna secularizada surge como um processo interno de reforma e estabilização das religiões universais, pois o que se mostra como forte exigência neste caso são as noções de coerência, coesão e unidade na visão do cosmos, sendo este identificado aqui com o aspecto monista do self protegido da modernidade, entre os quais hora ela tem os seus êxitos e hora os seus fracassos.

Então, internamente a este processo abrangente de disciplinarização social, racionalização e desencanto, é que temos o desdobramento consequentemente estrutural da visão de mundo secularizada. Isto significa que uma ordem impessoal e benevolente do cosmos natural e humano acaba sendo forjada como um paradigma epistemológico nominalista e voluntarista oriundo da crise da escolástica medieval que desemboca nas ações individualizantes da reforma protestante. Desta forma, temos a gradual legitimação de uma visão de mundo que não é vista apenas desde uma noção de ordem moral meramente 
antropocêntrica, mas em seu cunho de projeto humanista, num sentido exclusivista. Esta concepção esta comprometida em promover a construção de um estado de coisas onde a ordem moral moderna passa a agir de modo excludente, seletivo. Porém, Taylor insiste que a tarefa de compreendermos a vida espiritual nos dias atuais precisa levar em conta os seus mais variados impulsos, resistências e reações numa era secular que envolve a plenitude autorealizadora da vida de uma multidão de pessoas.

\section{REFERÊNCIAS BIBLIOGRÁFICAS}

ARAUJO, L. B. Leite. Esfera pública e secularismo: introduzindo a questão. In: Esfera pública e secularismo: ensaios de filosofia política / Organização, Luiz Bernardo Leite Araujo, Marcela Borges Martinez, Taís Silva Pereira. Rio de Janeiro: EdUERJ, 2012.

BITTAR, Eduardo C. B. Curso de filosofia política. 4. ed. São Paulo: Atlas, 2011.

BOBBIO, Norberto. A era dos direitos. Trad. Regina Lyra. Rio de Janeiro: Elsevier: Campus, 2004.

COSTA, P. Introducción. In: TAYLOR, C. Encanto y desencantamiento: secularidad y laicidad en Occidente. Traducción: José Pérez Escobar. Maliaño (Cantabria) - España: Editorial Sal Terrae, 2015.

HEIDEGGER, M. Ser e tempo. Tradução revisada e apresentação de Márcia Sá Cavalcante Schuback; posfácio de Emmanuel Carneiro Leão. 3. ed. - Petrópolis: Vozes; Bragança Paulista: Editora Universitária São Francisco, 2008.

PEREIRA, Taís Silva. O bem e o self: um estudo sobre a ontologia temporalizada da moral de Charles Taylor a partir do problema da motivação. Orientador: Luiz Bernardo Leite Araujo. Dissertação (mestrado) - Universidade do Estado do Rio de Janeiro, Instituto de Filosofia e Ciências Humanas, 2008. Disponível em: $<$ http://www.bdtd.uerj.br/tde_busca/arquivo. php?codArquivo=1819>. Acesso em: 25 dez. 2017.

RODRIGUES, E. Charles Taylor e a secularização como novas condições de crença. Religare. ISSN: 19826605, v.12, n.1, março de 2015, p.172-195. Disponível em: $<$ http://periodicos.ufpb.br/index.php/religare/article/view/27257/14590>. Acessado em: 03 fev. 2016.

RIBEIRO, E. Charles Taylor e a secularização. Brotéria: cristianismo e cultura, vol.170, n.2, fevereiro de 2010, p.147-156. Disponível em: $<$ http://www.broteria.pt/images/books/pdf/Broteria_Fevereiro2010.pdf $>$. Acessado em: 05 fev. 2016.

TAYLOR, C. Argumentos filosóficos. Tradução Adail Ubirajara Sobral. 2. ed. São Paulo: Edições Loyola, 2014.

. As fontes do self: a construção da identidade moderna. Tradução: Adail Ubirajara Sobral; Dinah de Abreu Azevedo. 4. Ed. Loyola: São Paulo, 2013a. 
. O espírito democrático em risco. In: IHU Online: Revista do Instituto Humanistas Unisinos, São Leopoldo, ano XIII, n. 426, p. 42-46, 2013 b. $\overline{2011}$

A ética da autenticidade. Tradução de Talyta Carvalho. São Paulo: É Realizações, . Uma era secular. Tradução de Nélio Schneider e Luzia Araújo. São Leopoldo, RS: Ed. UNISINOS, 2010.

. Las variedades de la religión hoy. Traducción de Ramón Vilá Vernis. Paidós, Barcelona, 2004.

. A Catholic Modernity? James L. Heft (eds). New York: Oxford, 1999. 